\title{
Pengelolaan Museum Negeri Siginjei Provinsi Jambi Sebagai Daya Tarik Wisata
}

\author{
M Rian Indra Eftritianto*, I Nyoman Wardi, Rochtri Agung Bawono \\ Prodi Arkeologi, Fakultas Ilmu Budaya, Unud \\ [rindraeftritianto@gmail.com],[wardiecoculture@gmail.com], \\ [rabawono@gmail.com] \\ Kota Jambi, Provinsi Jambi, Indonesia \\ *Corresponding Author
}

\begin{abstract}
Indonesian Museum was formed by European aristocrats who like to collect ancient objects during the Dutch colonialism, which is useful for preserving, fostering, and developing culture by tracing Indonesian culture. Starting from this, the Van Het Bataviaasch Genootschap Kunsten Wetenschappen Museum was founded on April 24, 1778 which was the first museum in the Indonesian Museum. Museum collections and cultural preservation objects must collaborate with other fields of science such as technology, geography, and history. The museum collection objects in Indonesia can be broadly divided into two types, namely general museums and special museums. The objective to be achieved in this research is to know the strategy of managing the Siginjei State Museum of Jambi Province as a tourist attraction in developing tourism in Jambi Province. The problem of Human Resources (HR) how to overcome it is by including the staff and employees of the Siginjei State Museum of Jambi Province in research and education about museums and foreign language courses. Based on the percentage obtained, $40.20 \%$ of respondents were in the number disagreeing with the total number of 725 who chose the category of disagreeing with some of the questions given, while $43.20 \%$ were in the number agreeing with the total number of 779 respondents. This percentage can be assumed that many visitors agreed with the management of the museum management and the condition of the Siginjei State Museum of Jambi Province itself.
\end{abstract}

Keywords: management, tourism, siginjei country, museum

\begin{abstract}
Abstrak
Permuseuman Indonesia dibentuk oleh para bangsawan Eropa yang hobi mengumpulkan bendabenda kuno pada saat penjajahan Belanda, yang berguna untuk pemeliharan, pembinaan, dan pengembangan kebudayaan dengan menelusuri kebudayan Indonesia. Bertolak dari hal ini, didirikanlah Museum Van Het Bataviaasch Genootschap Kunsten Wetenschappen pada 24 April 1778 yang merupakan museum pertama kali di Indonesia Museum. Untuk meningkatkan daya tarik wisata pada museum perlu dilakukan upaya pengembangan koleksi-koleksi maupun cagar budaya yang bersifat modern. Benda-benda koleksi museum maupun cagar budaya harus berkolaborasi dengan bidang ilmu lainya seperti teknologi, geografi, maupun sejarah. Bendabenda koleksi museum tersebut di Indonesia secara garis besarnya dapat dibagi menjadi dua jenis, yaitu museum umum dan museum khusus. Tujuan yang ingin dicapai dalam penelitian ini yaitu, mengetahui strategi pengelolaan Museum Negeri Siginjei Provinsi Jambi sebagai daya tarik wisata dalam mengembangkan pariwisata di Provinsi Jambi. Teknik pengumpulan tentang penelitian ini yaitu kuantitatif, dan S.W.O.T. Masalah Sumber Daya Manusia (SDM) cara mengatasinya yaitu dengan mengikutsertakan para staff dan pegawai Museum Negeri Siginjei Provinsi Jambi dalam penelitian maupun pendidikan tentang museum dan kursus bahasa asing. Berdasarkan presentase yang didapat, $40,20 \%$ responden berada di angka kurang setuju dengan
\end{abstract}

\begin{tabular}{lll}
\hline Info Article & & \\
\hline Received & $:$ & $15^{\text {th }}$ December 2019 \\
Accepted & $:$ & $10^{\text {th }}$ November 2020 \\
Published & $:$ & $30^{\text {th }}$ November 2020
\end{tabular}


total jumlah 725 yang memilih kategori kurang setuju terhadap beberapa pertanyaan yang di berikan, sedangkan $43,20 \%$ berada di angka setuju dengan total jumlah 779 responden. Presentase ini dapat diasumsikan bahwa banyak pengunjung yang setuju dengan manajemen pengelolaan museum maupun kondisi Museum Negeri Siginjei Provinsi Jambi itu sendiri.

Kata kunci: pengelolaan, pariwisata, negeri siginjei, museum

\section{PENDAHULUAN}

Museum memiliki peranan penting untuk menyelamatkan dan melestarikan warisan budaya serta menyediakan sarana komunikasi untuk mencerdaskan kehidupan masyarakat dan bangsa melalui pameran benda-benda koleksi budaya

Permuseuman Indonesia dibentuk oleh para bangsawan Eropa yang hobi mengumpulkan benda-benda kuno pada saat penjajahan Belanda, yang berguna untuk pemeliharan, pembinaan, dan pengembangan kebudayaan dengan menelusuri kebudayan Indonesia. Bertolak dari hal ini, didirikanlah Museum Van Het Bataviaasch Genootschap Kunsten Wetenschappen pada 24 April 1778 yang merupakan museum pertama kali di Indonesia (Munandar, 2011: 2).

Latar belakang berdirinya museum di Indonesia tersebut disebabkan oleh faktor keberagaman budaya bangsa Indonesia itu sendiri. Keberagaman budaya serta adat istiadat tersebut menjadikan Indonesia sebagai tujuan utama pariwisata. Akibatnya, Pemerintah Indonesia memprioritaskan museum sebagai objek pariwisata selain pariwisata alam. Hal ini didukung pula dengan ajakan atau himbauan dari Kementerian Kebudayaan dan Pariwisata melalui Ayo ke Museum. Program ini merupakan suatu strategi ampuh dari pemerintah untuk memperkuat revitalisasi museum sebagai objek wisata (Lutfi, 2008: 29-90).

Untuk meningkatkan daya tarik wisata pada museum perlu dilakukan upaya pengembangan koleksi-koleksi maupun cagar budaya yang bersifat modern. Benda-benda koleksi museum maupun cagar budaya harus berkolaborasi dengan bidang ilmu lainya seperti teknologi, geografi, maupun sejarah. Benda-benda koleksi museum tersebut di Indonesia secara garis besarnya dapat dibagi menjadi dua jenis, yaitu museum umum dan museum khusus (Irdana, 2018: 132-147. Museum umum ialah museum yang koleksinya terdiri atas kumpulan bukti benda tinggalan manusia masa lalu dan lingkungannya yang berkaitan dengan lebih dari satu cabang seni, displin ilmu, dan teknologi. Museum khusus adalah museum yang koleksinya terdiri atas kumpulan bukti benda tinggalan manusia masa lalu atau lingkungannya yang berkaitan dengan satu cabang teknologi (Amir, 1989 : 10). Adapun salah satu museum yang bersifat umum antara lain adalah Museum Negeri Siginjei Provinsi Jambi.

Museum Negeri Siginjei Provinsi Jambi pertama kali pembangunannya 18 Februari 1981 Oleh Gubernur Kepala Daerah Tingkat Satu Provinsi Jambi, Bapak Masychun Sifian SH, menjadi pertanda berdirinya museum di Provinsi Jambi. Museum Negeri Siginjei Provinsi Jambi terletak di tempat yang sangat strategis yaitu masih di daerah perkantoran Provinsi Jambi, atau lebih tepatnya di perempatan Jalan Yusuf Singadikane, Jalan Prof. Dr. Sri Sudewi, Jalan Urip Sumoharjo, dan Jalan Slamet Riyadi.

Museum Negeri Siginjei Provinsi Jambi ini memiliki koleksi bersejarah. Berdasarkan koleksi yang ada di Museum Negeri Siginjei Provinsi Jambi antara lain: koleksi geologika, biologika, 
etnografika, dan arkeologika. Museum Negeri Siginjei Provinsi Jambi merupakan salah satu daya tarik wisata yang disuguhkan oleh Pemerintah Daerah Jambi. Pemanfaatan Museum Siginjei sebagai objek wisata tentunya memiliki nilai dan dampak baik positif maupun dampak negetif, bagi masyarakat Jambi pada khususnya (Yosua, 2018: 15-30).

Museum Negeri Siginjei Provinsi Jambi ini memiliki koleksi bersejarah. Berdasarkan koleksi yang ada di Museum Negeri Siginjei Provinsi Jambi antara lain: koleksi geologika, biologika, etnografika, dan arkeologika. Museum Negeri Siginjei Provinsi Jambi merupakan salah satu daya tarik wisata yang disuguhkan oleh Pemerintah Daerah Jambi (Akbar, 2010: 50-100). Pemanfaatan Museum Siginjei sebagai objek wisata tentunya memiliki nilai dan dampak baik positif maupun dampak negetif, bagi masyarakat Jambi pada khususnya.

Permasalahan dalam pemanfaatan Museum Negeri Siginjei Provinsi Jambi yaitu bagaimana strategi pengelolaan Museum Negeri Siginjei Provinsi Jambi sebagai daya tarik wisata?. Tujuan Penelitian Untuk mengetahui strategi pengelolaan Museum Negeri Siginjei Provinsi Jambi sebagai daya tarik wisata dalam mengembangkan pariwisata di Provinsi Jambi.

Metode penelitian ini menggunakan beberapa metode analisis untuk mengolah data yang didapatkan. Analisis yang digunakan yaitu analisis kuantitatif, dan S.W.O.T. Analisis Analisis kuantitatif adalah suatu cara menganalisis terhadap informasi yang diperoleh dari kuesioner yang dilakukan kepada sejumlah responden (Adrianto, 2018: 226-238). Analisis ini digunakan pembuatan tabulasi atas data-data yang diperoleh di lapangan. Setelah itu data diolah dan ditabulasikan, kemudian dimasuk ke dalam tabel dan dihitung frekuensi serta persentasenya. Sedangkan analisis S.W.O.T ialah mengidentifikasi berbagai faktor secara sistematis untuk merumuskan strategi perusahan. Analisis ini didasarkan pada logika yang dapat memaksimalkan kekuatan (Strenght) dan peluang (Opportunity), namun secara bersama dapat meminimalkan kelemahan (Weakness) dan ancaman (Threats). Proses pengambilan keputusan strategis selalu berkaitan dengan pengembangan misi, tujuan, strategi, dan kebijakan (Okvita, 2016: 1-13).

\section{KERANGKA TEORI}

Penelitian ini juga menggunakan dua teori yaitu teori pariwisata dan teori manajemen. Tori pariwisata adalah Pengembangan pariwisata dalam negeri telah diarahkan untuk memupuk cinta tanah air dan bangsa, menanamkan jiwa dan semangat serta nilai-nilai luhur berbangsa, meningkatkan kualitas budaya bangsa, memperkenalkan peninggalan sejarah, keindahan alam termasuk bahari dengan terus meningkatkan wisata remaja-remaja pemuda (Muljadi, 2009 : 31). Pengembangan pariwisata dalam penelitian ini untuk mengetahui potensi Museum Negeri Siginjei Provinsi Jambi sebagai daya tarik wisata. Pengembangan terhadap potensi Museum Negeri Siginjei Provinsi Jambi bertujuan untuk memupuk rasa nasionalisme, dan juga meningkatkan kualitas budaya bangsa serta sejarah bangsa Indonesia. Sedangkan Teori manajemen museum adalah suatu perencanaan, pengorganisasian, pengkoordinasian, pelaksanaan dan pengawasan terhadap pengadaan, pengembangan, pemberian balas jasa, pengintegrasian, pemeliharaan, dan pemisahan tenaga kerja dalam rangka mencapai tujuan organisasi (Mangkunegara, 2012:2). digunakan untuk menjawab permasalahan Pengelolaan Museum Negeri Siginjei Provinsi Jambi sebagai 
daya tarik wisata. Proses pengelolaan museum yang baik diharapkan mampu menjawab perubahan paradigma pengelolaan yang sedang berjalan saat ini (Alexander, 2015: 13-40).

\section{HASIL DAN PEMBAHASAAN}

\section{Gambaran Museum Negeri Siginjei Provinsi Jambi}

Masyarakat Jambi memiliki banyak suku dan budaya yang mendiaminya, diantaranya adalah suku Kerinci, suku Kubu, suku Batin, suku Melayu, dan beberapa suku minoritas lainya. Pada abad ke-4, agama buddhis telah masuk di Provinsi Jambi yang dikuasai oleh zaman Kerajaan Sriwijaya, bukti yang ada sekarang berupa bangunan candi di Muaro Jambi dan juga dikatakan oleh pendeta Tiongkok, I-Tsing menulis bahwa ia mengunjungi Kerajaan Sriwijaya dan tinggal selama 6 bulan untuk mempelajari keagamaan. Setelah Kerajaan Sriwijaya runtuh munculnya agama Islam yang mulai pelan-pelan menyebarkan ajaran Islam ke masyarakat Jambi

Museum Negeri Siginjei merupakan tempat penyimpanan tinggalan kebudayaan masyarakat Jambi dengan tugas untuk merawat, memelihara, dan mempromosikan kepada masyarakat Indonesia ataupun masyarakat Jambi untuk mengetahui kebudayaan Jambi masa lalu. Nama Museum Negeri Siginjei Provinsi Jambi ini memiliki sebuah arti tentang kebudayaan Jambi.

Lokasi Museum Negeri Siginjei Provinsi Jambi dimiliki oleh organisasi Persatuan Pamong Marga Desa (PPMD) Jambi. Persatuan Pamong Marga Desa Jambi dengan ikhlas menyerahkan/menghibahkan lokasi tersebut untuk pembangunan museum yang terletak di perempatan Jalan Jenderal Urip Sumoharjo, Sungai Putri, Telanaipura, Provinsi Jambi. Museum
Negeri Siginjei Provinsi Jambi memiliki luas $13.350 \mathrm{~m} 2$. Secara astronomis Museum Negeri Siginjei Provinsi Jambi berada pada koordinat $1^{\circ} 36^{\prime} 27.5^{\prime \prime} \mathrm{S}$ dan $103^{\circ} 35^{\prime} 3.3^{\prime \prime}$ E. Museum Negeri Siginjei Provinsi Jambi terletak di dekat wilayah perkantoran Provinsi Jambi, Pusat Pendidikan, Rumah walikota, dan Rumah penduduk sekitar Museum Negeri Siginjei Provinsi Jambi (Muliadi, 2016: 58-61).

Jam berkunjung wisatawan dibuka pukul 08:00 hingga pukul 15:00 WIB. Jam berkunjung tersebut berlaku pada hari senin sampai kamis. Sedangkan jadwal berkunjung akan dibatasi hingga pukul 11:00 WIB apabila hari jumat, dan pada hari sabtu jam berkunjung wisatawan hingga pukul 12:00 WIB. Museum Negeri Siginjei Provinsi Jambi tidak beroperasi di hari minggu. Selain itu biaya kunjungan wisatawan berlaku untuk masin-masing golongan dengan klasifikasi umur sebagai berikut : biaya dewasa perorangan sebesar Rp 2.000, anak-anak perorangan sebesar $\mathrm{Rp} 1.500$, dan biaya dewasa rombongan sebesar Rp 1.500, anak-anak rombongan sebesar $\mathrm{Rp}$ 1.000 , dan wisata asing rombongan sebesar Rp 2.000 (Tunggul, 2017: 7-11).

\section{Pengelolaan Provinsi Jambi \\ Museum Siginjei}

Pengelolaan Museum Negeri Siginjei dikelola oleh pemerintah Provinsi Jambi dan berada di bawah pengawasan Dinas Kebudayaan dan Pariwisata Provinsi Jambi (Goulding, 2000: 261-278).

Jumlah staf yang ada di museum saat ini sebanyak 29 orang dengan tingkat pendidikan yang berbeda, yaitu SMP 2 orang, SMA 4 orang, Sarjana S1 20 orang dan Sarjana S2 3 Orang. Menurut informasi mengatakan bahwa staf yang ada di museum masih kurang untuk mengembangkan Museum Negeri Siginjei Provinsi Jambi, dikarenakan tim ahli di bidang Arkeologi maupun di 
bidang yang membantu untuk pengembangan pariwisata, hanya ada beberapa saja yang berkompeten untuk mengembangkan museum. sehingga sangat perlu untuk ditambah agar pembagian tugasnya merata dan dalam struktur tersebut terjabarkan pembagian tugas setiap staf dengan jelas (Mantitaputy, 2010: 25-34). Kunjungan wisatawan Museum Negeri Siginjei, tiap tahun mengalami penurunan dan peningkatan kunjungan Museum Negeri Siginjei. Pada Tahun 2016 jumlah kunjungan wisatawan dengan jenjang pendidikan TK/SD, SLTP, SMA/SK, perguran tinnggi, peneliti, tamu negara, instansi dan tamu daerah, wisatawan asing, dan wisatawan nusantara/umum sebesar 16.772. Jumlah kunjungan tersebut mengalamin peningkatan 2017 sebanyak 22.474. Namun pada tahun 2018 mengalamin penurunan dratis, kunjungan wisatawan 13.802. Jadi total kunjangan wisatawan TL/SD, SLTP, SMA/SK, Perguraan Tinggi, Peneliti, Tamu Negara, Instansi dan Tamu Daerah, Wisatawan Asing, dan Wisatawan Nusantara/Umum selama 3 tahun terakhir sebanyak 54.676. Pada di tahun 2016 jumlah pengujung mengatasnamakan peneliti sekitar 1.126. Namun pada tahun 2017-2018 pengujung yang mengatasnamakan peneliti tidak ada, dikarenakan faktor kesalahaan teknis saat pengisian buku tamu. Peningkatan kunjungan wisatawan dalam 3 tahun terakhir disebabkan oleh beberapa kegiatan event mancanegara Provinsi Jambi seperti perayaan keagamaan umat Budha yang ada di Kompleks Candi Muaro Jambi, tetapi juga mereka mengunjungi Museum Negeri Siginjei Provinsi Jambi.

S.W.O.T merupakan alat analisis yang digunakan untuk mengkaji dan mengidentifikasi Museum Negeri Siginjei Jambi sebagai daya tarik wisata. Analisis mencakup faktor internal strengths dan weakness serta faktor eksternal opportunities dan threats yang dimiliki Museum Negeri Siginjei (Rangkuti. 2011: 20-43).

Masalah Sumber Daya Manusia (SDM) cara mengatasinya yaitu dengan mengikutsertakan para staff dan pegawai Museum Negeri Siginjei Provinsi Jambi dalam penelitian maupun pendidikan tentang museum dan kursus bahasa asing.

Masalah keamanan koleksi, pengunjung dan perawatan terhadap koleksi harus lebih dikembangkan kembali.

Masalah sarana dan prasaran penunjang yaitu dengan cara memperbaiki saran dan prasarana yang ada dan membuat akses untuk kursi roda, informasi berhuruf braille, ruang bermain anak, ruang ibu menyusui dan penunjukpenunjuk arah untuk sarana dan prasaran yang ada. (Nanag, 2012: 313-317).

Masalah terbatasnya media informasi dan promosi cara mengatasinya yaitu dengan membuat sebuah pusat media informasi untuk Museum Negeri Siginjei Provinsi Jambi, menyebarkan brosur, pamplet ke sekolah-sekolah, travel-travel agen, dan universitas serta mengadakan kerjasama dengan pihak-pihak instansi, komunitas, dan organisasi untuk membuat kegiatan di Museum Negeri Siginjei Provinsi Jambi (Munanda, 2017: 187-198).

Hasil kuesioner pengunjung dalam penelitian ini berperan sebagai data pendukung untuk memberikan manfaat yang dapat dijadikan pandangan serta pertimbangan dalam pemanfaatan Museum Negeri Siginjei sebagai daya tarik wisata (Saptono, 2012: 313-317).

Berdasarkan hasil kusioner dominan rosponden memilih di angka kurang setuju dan setuju. Berdasarkan presentase yang didapat, 40,20\% responden berada di angka kurang setuju dengan total jumlah 725 yang memilih kategori kurang setuju terhadap beberapa 
pertanyaan yang di berikan, sedangkan $43,20 \%$ berada di angka setuju dengan total jumlah 779 responden. Presentase ini dapat diasumsikan bahwa banyak pengunjung yang setuju dengan manajemen pengelolaan museum maupun kondisi Museum Negeri Siginjei Provinsi Jambi itu sendiri (Maulana, 2018: 215-235).

\section{SIMPULAN}

Berdasarkan penelitian di atas, maka akan diuraikan mengenai kesimpulan permasalahan yang dikaji dalam penelitian ini: Museum Negeri Siginjei Provinsi Jambi dalam menunjang pengembangan pariwisata yaitu melalui kegiatan-kegiatan yang bisa masyarakat berkunjung ke museum dan bisa melaksanakan kegiatan konservasi benda cagar budaya yaitu pelestarian fisik dan pelestarian terhadap makna yang terkandung di dalam koleksi Museum Negeri Siginjei Provinsi Jambi yang menunjang pendidikan dalam mencerdaskan, memperkenalkan dan menumbuhkan rasa cinta akan nilai-nilai luhur dari warisan budaya, dan menyediakan sumber informasi. Pengelolaan yang ada di Museum Negeri Siginjei Provinsi Jambi sudah baik, namun ada beberapa hal yang masih harus diperbaiki antara lain museum harus mencari cara lain dalan menambah pemasukan bagi museum, peningkatan perawatan terhadap sarana dan prasarana yang ada di Museum Negeri Siginjei Provinsi Jambi, dan perlu adanya promosi yang lebih giat dan gencar.

\section{REFERENSI}

Yosua, Adrian. (2018). Kampanye Kesadaran Masyarakat Mengenai Pelestarian Cagar Budaya Berdasarkan Undang-Undang No 11 Tahun 2010. Kalpataru Majalah
Arkeologi. Vol 27 No. 1, 2018 (1530).

Adrianto. (2018). Manajemen Program Pengembangan Distinasi Pariwisata Oleh Dinas Pariwisata, Kebudayaan, Pemuda dan Olahraga Kabupaten Kerinci. JAKP (Jurnal Administrasi dan Kebijakan Publik), Vol III No 3, 2018. (226238)

Lutfi, Asianto. (2008). Pedoman Museum Indonesia. Jakarta: Direktur Jenderal Sejarah dan Purbakal.

Akbar, Ali. (2010). Museum Di Indonesia Kendala dan Harapan. Jakarta: Papas Sinar Sinanti.

Goulding, C. (2000). The museum environment and the visitor experience. European Journal of Marketing, 34(3/4), 261-278.

Irdana, Nuryuda, (2018). Konsep Penataan Koleksi Museum Untuk Mempermudah Pemahaman Wisatawan Dalam Wisata Edukasi Arsip dan Koleksi Perbankan di Museum Bank Mandiri Jakarta. Diplomatika, Vol1, No 2, 2018. (132-147).

Alexander, Joseph. (2015). Persepsi Kualitas Layanan Museum Di Indonesia: Sebuah Studi Observasi. Jurnal Manajemen, Vol 12, No 1, 2015. (13-40).

Muljadi, A.J. (2009). Kepariwisataan dan Perjalanan. Jakarta: PT Raja Grafindo Persada

Mantitaputy. (2010). Pentingnya Museum Bagi Pelestarian Warisan Budaya dan Pendidikan Dalam Pembangunan. Kapata Arkeologi. 
Vol 23, No 3. November 2010 (25$34)$.

Munandar, A. A. (2011). Sejarah Permuseuman di Indonesia. Jakarta: Direktorat Jenderal Kebudayaan.

Mangkunegara, A.A Anwar Prabu. (2012). Manajemen Sumber Daya Manusia. Bandung: PT. Remaja Rosdakarya.

Okvita, Andini. (2016). Pengelolaan Fasilitas Museum Sultan Syarif Kasim Di Kabupaten Bengkalis. JOM FISIP Vol. 3 No. 2. 2016(113).

Munanda, Nenggala. (2017). Strategi Pengembangan Potensi dan Daya Tarik Wisata Museum Tuanku Imam Bonjol DI Kabupaten Pasaman, JOM Fekon Vol. 4 No. 1, 2017 (187-198).

Muliadi, I Nyoman. (2016). Pengelolaan Museum Arma Sebagai Daya Tarik Wisata Budaya Di Desa Ubud, Jurnal Destinasi Pariwisata, Vol. 4 No 2, 2016, (58-61).

Tunggul, $\quad$ Prasodjo. (2017). Pengembangan pariwisata Budaya Dalam Perspektif Pelayanan Publik.Jurnal Office, Vol 3, No 1, 2017. (7-11).

Rangkuti, Freddy. (2011). Analisis SWOT Teknik Membedah kasus Bisnis. Jakarata: PT Gramedia Pustaka Utama

Amir, Sutarga. (1990). Studi Museologi, Jakarta: Direktorat Jendral Kebudayaan Departemen Pendidikan dan Kebudayaan.
Saptono, Nanang. (2012). "Penelitian Pengembangan Sumberdaya Arkeologi Mengenai Konsep Pengelolaan Berbasis Pembangunan Berkelanjutan". Prosiding Arkeologi Untuk Publik. Jakarta: Ikatan Ahli Arkeologi Indonesia. Hal 313-317.

Maulana, Yusuf. (2018). Pemanfaatan Museum Sebagai Sumber Belajar Dalam Pembelajaran Sejarah. Jurnal Visipena Volume 9, No 2, 2018. (215-235). 